\title{
Different protein expression associated with chemotherapy response in oropharyngeal cancer according to HPV status
}

Min-Jee Kim', Myung-Seo Ki ${ }^{1}$, Karham Kim, Hyun-Jeong Shim, Jun-Eul Hwang ${ }^{1}$, Woo-Kyun Bae', Ik-Joo Chung ${ }^{1}$, Dong-Hoon Lee², Joon-Kyoo Lee², Tae-Mi Yoon², Sang-Chul Lim², Woong-Ki Chung ${ }^{3}$, Jae-Uk Jeong ${ }^{3}$, Hoi-Soon Lim ${ }^{4}$ Yoo-Duk Choi ${ }^{5}$ and Sang-Hee Cho ${ }^{1^{*}}$

\begin{abstract}
Backgound: Oropharyngeal cancer (OPC) associated with human papilloma virus (HPV OPC) shows better treatment outcomes than non-HPV OPC. We investigated the expression of p53, $\beta$-tubulin, bcl-2 and ERCC 1 , which are well-known biomarkers to predict the chemotherapy response, according to HPV status in OPC patients.

Methods: Patients who treated with at least 2 cycles of induction chemotherapy followed by concurrent chemoradiotherapy for locally advanced oropharyngeal cancer were reviewed. HPV PCR and immunohistochemical stain was done in paraffin embedded tumor tissue and evaluated the relation with the chemotherapy response and survival outcomes according to HPV status.

Results: Seventy-four patients were enrolled for this study and all patients received induction chemotherapy with docetaxel, 5-FU and cisplatin. After induction chemotherapy, complete response (CR) was shown in 22 patients (30\%) and partial response (PR) in 46 patients (62\%). HPV + was detected in 21 patients (28\%), while 35 patients (47\%) showed p16+ expression by IHC analysis. p16 positive patients showed better overall response, PFS and OS than p16 negative patients. p53 and class III beta-tubulin expression were significantly higher in HPV- and p16- than HPV + and p16+ patients. Conversely, bcl-2 expression was greater in HPV + or p16+ than HPV- or p16- patients. ERCC1 expression did not differ significantly according to HPV status. In multivariate analyses, early T stage $(p=0.036)$ and good PS (PS 0$)(p=0.029)$ showed a better 3Y-PFS rate, and low p53 expression $(p=0.012)$ and complete response after induction chemotherapy $(p=0.026)$ were highly associated with 3Y-OS rate. Low expression of p53 and p16 positive patients showed significantly prolonged OS than others $(p=0.010)$.

Conclusion: P53, class III beta-tubulin and bcl-2 were differently expressed in OPC according to HPV status and present study suggested the underlying mechanism of better response to chemotherapy in case of HPV OPC than non-HPV OPC. Among these biomarkers, p53 is the strongest prognostic marker in OPC and p53 in addition to p16 support the rationale to study of de-escalation strategy for OPC.
\end{abstract}

Keywords: Oropharyngeal cancer, HPV, p16, Chemotherapy, p53, Beta tubulin, bcl-2

\footnotetext{
* Correspondence: shcho@jnu.ac.kr

'Department of Hematology-Oncology, Chonnam National University Hwasun Hospital, 322 Seoyangro, Hwasun, Jeollanamdo 519-763, Republic of Korea

Full list of author information is available at the end of the article
} 


\section{Background}

Among the head and neck cancers, which are well known for their heterogeneity, oropharyngeal cancer (OPC) has been reevaluated because its pathogenesis is associated with human papilloma virus (HPV). The incidence of oropharyngeal squamous cell carcinoma has increased over the past few decades in western countries as well as in Asia including Korea, particularly in younger adults and non-smokers [1-3]. Reliable evidence suggests that OPC associated with HPV (HPV OPC) has a better prognosis than non-HPV-associated OPC (non-HPV OPC) [4-6]. HPV OPC may have different epidemiological and histopathological characteristics than other head and neck cancers, which are usually associated with smoking and alcohol use $[7,8]$. The molecular profiles of HPV OPC are characterized by p53 degradation, retinoblastoma RB pathway inactivation by E6 and E7 oncoprotein overexpression, respectively and p16 upregulation [9]. In contrast, non-HPV OPC is associated with smoking-induced multistep carcinogenesis, such as frequent TP53 mutations and p16 impairment [10]. HPV OPC responds better to chemotherapy and radiotherapy, which can be in part explained by non-mutant TP53 $[11,12]$, absence of field cancerization related to tobacco use and functional p53-mediated apoptotic pathways [13] unlike non-HPV OPC occurring in younger patients, which has fewer comorbidities and a better performance status. However, biomarkers for chemotherapy response in OPC according to HPV status have not been identified.

In locally advanced or unresectable head-and-neck cancers, docetaxel, cisplatin and 5-FU (DCF) has been used as an induction chemotherapy, and showed a high response rate and improved survival [14,15]. p53 is a well-known prognostic factor and predictive marker of a response to chemotherapy in head-and-neck squamous cell carcinoma (HNSCC), including OPC [16,17]. In addition, the effects of class III beta-tubulin on taxane and ERCC1 on platinum-based chemotherapy have been investigated in various tumors, including those of the stomach and lung [18-20]. High expression of bcl-2 is reportedly a favorable prognostic factor [21] in head-andneck cancers. Therefore, in this study we evaluated the expression of these biomarkers according to HPV status and the ability to predict the response to chemotherapy in OPC patients treated with induction chemotherapy using DCF followed by concurrent chemoradiotherapy (CCRT). We also identified the optimal surrogate marker to predict the prognosis of HPV OPC.

\section{Methods}

Patients ( $\geq 18$ years of age) diagnosed with locally advanced OPC between June 2004 and December 2011 were reviewed retrospectively. Inclusion criteria for this study were a diagnosis of squamous cell carcinoma, tumor stage III to IV according to the American Joint Committee on Cancer Staging [22], treatment with at least two cycles of induction DCF chemotherapy with or without following CCRT, evaluation of the response to induction chemotherapy, paraffin-embedded tumor tissue available at diagnosis and informed consent provided, a Karnofsky performance status (KPS) $\geq 70$ at diagnosis, and sufficient organ function to undergo chemoradiotherapy (CRT). Exclusion criteria included disease location other than the oropharynx, other confirmed or suspected malignancies or a cancer other than squamous carcinoma. Data regarding patients' characteristics, chemotherapy response, progression-free survival (PFS), and overall survival (OS) were obtained from medical records.

Induction chemotherapy was administered using docetaxel $\left(70 \mathrm{mg} / \mathrm{m}^{2}\right.$ on Day 1$)$, cisplatin $\left(75 \mathrm{mg} / \mathrm{m}^{2}\right.$ on Day 1$)$ and 5 -FU $\left(1000 \mathrm{mg} / \mathrm{m}^{2}\right.$ on Day $\left.1-4\right)$ repeated every 3 weeks for up to three cycles. Chemotherapy was discontinued in patients who did not respond to induction chemotherapy, and salvage surgery or radiotherapy was performed. After induction chemotherapy, definitive treatment such as CCRT or surgery was performed based on a consensus of the multidisciplinary head-and-neck cancer team. Standard radiotherapy was started within 4 weeks of induction chemotherapy completion and wide treatment fields were planned to encompass the primary tumor site and neck area involved. Treatment consisted of a single daily isocentric external-beam megavoltage irradiation administered at 1.8 to 2.0 Gy per fraction. The primary tumor and affected neck area received 65 to $70 \mathrm{~Gy}$. A minimum of 45 Gy was delivered bilaterally to clinically uninvolved neck areas and supraclavicular regions. Definite irradiation was scheduled with concurrent administration of cisplatin in all patients, except for those with a performance status or residual toxicity precluding the co-administration of chemotherapy. Cisplatin was administered every 3 weeks at a dose of $100 \mathrm{mg} / \mathrm{m}^{2}$ depending on creatinine clearance. Cisplatin administration was delayed if evidence of dehydration, renal toxicity, neurotoxicity or ototoxicity was present. For patients with grade $3 / 4$ mucositis or dysphagia, radiation therapy was delayed until recovery to less than grade 2 toxicity. Patients with disease progression or for whom definitive treatment was not available received further chemotherapy as palliative care.

The response evaluation was based on the Response Evaluation Criteria in Solid Tumors (RECIST 1.1) and was assessed after induction chemotherapy and 8 weeks later, following completion of CRT. For all patients with a complete response (CR) on physical examination and CT or MRI scan, a $\left[{ }^{18} \mathrm{~F}\right]$ fluorodeoxyglucose positron emission tomography $\left({ }^{18}\right.$ F-FDG-PET) scan was performed for confirmation at 1 month after confirmation of CR. Upon completion of treatment, patients were followed-up 
monthly by physical examination and CT or MRI scanning was performed every 4 months for 2 years and twice annually thereafter until disease progression. This study was approved by the Institutional Review Board of Chonnam National University Hwasun Hospital (CNUHH-2014-041).

\section{HPV detection and genotyping}

Oropharyngeal cancer tissues were reviewed by the pathologist and tumor cells were identified by light microscopic examination. Before genomic DNA extraction, $20 \mu \mathrm{m}$ paraffin sections were incubated from the formalin-fixed paraffin-embedded tissue using the QIAGEN Multiplex PCR kit (QIAGEN, Germany) with specific HPV primer sets. All multiplex PCR reactions were followed by manufacturer instructions. Each PCR was carried out in a DNA thermal cycler (PCR thermal cycler Dice, Takara, Japan) with the following conditions: denaturing at 95 for $15 \mathrm{~min} ; 10$ cycles of $30 \mathrm{~s}$ at 94, $90 \mathrm{~s}$ at 63, and 90 at 72; and extension at 72 for $10 \mathrm{~min}$. PCR products were analyzed by electrophoresis on a $2 \%$ agarose gel containing ethidium bromide. HPV type was designated based on the band pattern. In cases where band interpretation was not clear, an additional PCR amplification with specific primers was performed to confirm. Selected PCR amplified fragments were cloned into pCR 2.1 vector (Invitrogen, USA), each cloned product was sequenced to confirm fragment identity. Primers for each reaction were followed as previous report [23].

\section{Immunochemistry}

Automated immunohistochemical staining was performed using the Bond-max system (Leica Microsystems, Bannockburn, IL), which is able to process up to 30 slides at a time. Slides carrying the $2-\mu \mathrm{m}$ thickness tissue sections cut from paraffin-embedded tissue blocks were labeled and dried for 1 hour at $60^{\circ} \mathrm{C}$. These slides were then covered by Bond Universal Covertiles (Leica Microsystems) and placed into the Bond-max instrument. All subsequent steps were performed by the automated instrument according to the manufacturer's instructions (Leica Microsystems), in the following order: (1) deparaffinization of the tissue slides with Bond Dewax Solution (Leica Microsystems) at $72^{\circ} \mathrm{C}$ for 30 minutes; (2) heat-induced epitope retrieval (antigen unmasking) with Bond Epitope Retrieval Solution 1 (Leica Microsystems) for 20 minutes at $100^{\circ} \mathrm{C}$; (3) peroxide block placement on the slides for 5 minutes at ambient temperature; and (4) incubation with P53 (1:1200 dilution, DO-7, DAKO, Denmark), Class III beta-tubulin (1:1000 dilution, TUJI, Convance, Princeton, NJ. USA), ERCC1 (1:1000 dilution, 8 F1, Abcam, Cambridge, UK), Bcl-2 (1:500 dilution, 124, DAKO, Denmark), and p16 (1:50 dilution,
G175-407, BD PharMingen, Sandiego, CA, USA) primary antibody for 15 minutes at ambient temperature; (5) incubation with Post Primary reagent (Leica Microsystems) for 8 minutes at ambient temperature, followed by washing with Bond Wash solution (Leica Microsystems) for 6 minutes; (6) Bond Polymer (Leica Microsystems) placement on the slides for 8 minutes at ambient temperature, followed by washing with Bond Wash and distilled water for 4 minutes; (7) color development with DAB (3,3'-diaminobenzidine tetrahydrochloride) chromogen for 10 minutes at ambient temperature; and (8) hematoxylin counterstaining for 5 minutes at ambient temperature, followed by mounting of the slides. Normal human serum served as a negative control.

\section{Evaluation of immunohistochemical staining}

The evaluation of all immunohistochemical staining was done as a blind assessment and independently by two authors. Any discordant findings between the two observers were settled using a conference microscope. Discordance between the two examiners never exceeded $10 \%$. For p53 and ERCC1, nuclear staining was regarded as positive, but, for $\mathrm{Bcl}-2$ and class III beta-tubulin, cytoplasmic staining was positive. Assessment of staining of p53, ERCC1, Bcl-2 and class III beta-tubulin was evaluated based on the staining intensity (SI). SI was scored

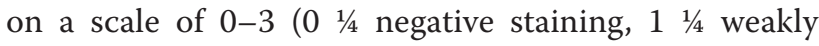
positive staining, $2 \frac{1}{4}$ moderately positive staining, and $3 \frac{1 / 4}{4}$ strongly positive staining). The intensity of staining was evaluated according for to the maximum intensity among positive cells. Tumors were categorized as high expression (SI: 2, 3) or low expression (SI: 0, 1). The immunoreactivity of p16 was evaluated as described previous method [24]. Positive was defined as strong and diffuse nuclear and cytoplasmic staining in $80 \%$ or more of the tumor cells.

\section{Statistical analysis}

Association analyses among HPV status, protein expression, and clinicopathological parameters were performed using the chi-square test and Fisher's exact test. Survival curves (OS and PFS) were calculated using the KaplanMeier method and curves were compared using the logrank test. OS was defined as the period from the time of diagnosis to the time of death or last follow-up. PFS was defined as the time from treatment initiation to tumor progression. Univariate analysis was performed using Kaplan-Meier method and log-rank test. All variables from univariate analysis showing $p$ values $<0.1$ were incorporated in the multivariate Cox hazard regression model with a step-wise forward procedure. SPSS version 20.0 (IBM, Inc., Chicago, IL, USA) was used for statistical analyses. A $p$-value $<0.05$ was considered to indicate statistical significance. 
Table 1 Patient and clinicopatholgic characteristics

\begin{tabular}{|c|c|c|c|c|c|c|c|}
\hline \multirow{2}{*}{$\begin{array}{l}\text { Patient } \\
\text { demographics }\end{array}$} & \multirow{2}{*}{$\begin{array}{l}\text { Total } \\
n(\%)\end{array}$} & \multicolumn{3}{|c|}{ HPV status, $n(\%)$} & \multicolumn{3}{|c|}{ p16 status, $n(\%)$} \\
\hline & & Positive & Negative & $p$ & Positive & Negative & $p$ \\
\hline Age ( $Y$, median) & & & & $<0.001$ & & & $<0.001$ \\
\hline$\geq 70 Y$ & 70 & 56 & 65 & & 57 & 68 & \\
\hline Range & $43-80$ & $43-77$ & $43-80$ & & $43-77$ & $48-80$ & \\
\hline Gender & & & & 0.135 & & & 0.147 \\
\hline Male & $69(93)$ & $18(86)$ & $51(96)$ & & $31(89)$ & $38(97)$ & \\
\hline Female & $5(7)$ & $3(14)$ & $2(4)$ & & $4(11)$ & $1(3)$ & \\
\hline Alcohol & & & & 0.366 & & & 0.292 \\
\hline Never/ social & $56(76)$ & $17(81)$ & $39(74)$ & & $28(80)$ & $28(72)$ & \\
\hline Heavy & $18(24)$ & $4(19)$ & $14(26)$ & & $7(20)$ & $11(28)$ & \\
\hline Anatomic site & & & & 0.376 & & & 0.692 \\
\hline Tonsil & $47(64)$ & $15(71)$ & $32(60)$ & & $24(69)$ & $23(59)$ & \\
\hline Soft palate & $10(13)$ & $1(5)$ & $9(17)$ & & $4(11)$ & $6(15)$ & \\
\hline Tongue base & $17(23)$ & $5(24)$ & $12(23)$ & & $7(20)$ & $10(26)$ & \\
\hline Clinical stage & & & & 0.366 & & & 0.502 \\
\hline III & $18(24)$ & $4(24)$ & $14(26)$ & & $9(26)$ & $9(23)$ & \\
\hline IV & $56(76)$ & $56(76)$ & $39(74)$ & & $26(74)$ & $30(77)$ & \\
\hline T stage & & & & 0.181 & & & 0.062 \\
\hline $\mathrm{T} 1-2$ & $45(61)$ & $15(71)$ & $30(57)$ & & $25(71)$ & $20(51)$ & \\
\hline T3-4 & $29(39)$ & $6(29)$ & $23(43)$ & & $10(29)$ & $19(49)$ & \\
\hline N stage & & & & 0.305 & & & 0.601 \\
\hline No-1 & $19(26)$ & $4(19)$ & $15(28)$ & & $9(26)$ & $10(26)$ & \\
\hline $\mathrm{N} 2-3$ & $55(74)$ & $17(81)$ & $38(72)$ & & $26(74)$ & $29(74)$ & \\
\hline Differentiation & & & & 0.346 & & & 0.099 \\
\hline Well & $23(31)$ & $4(19)$ & $19(36)$ & & $14(40)$ & $10(26)$ & \\
\hline Moderate & $19(26)$ & $6(29)$ & $13(25)$ & & $6(17)$ & $17(44)$ & \\
\hline Poorly & $8(11)$ & $4(19)$ & $4(8)$ & & $10(29)$ & $9(23)$ & \\
\hline NA & $24(32)$ & $7(33)$ & $17(32)$ & & $5(14)$ & $3(7)$ & \\
\hline PS & & & & 0.007 & & & 0.001 \\
\hline 0 & $42(57)$ & $17(81)$ & $25(47)$ & & $27(77)$ & $15(38)$ & \\
\hline 1 & $32(43)$ & $4(19)$ & $28(53)$ & & $8(23)$ & $24(62)$ & \\
\hline HPV & & & & & & & $<0.001$ \\
\hline Positive & $21(28)$ & $21(100)$ & 0 & & $21(60)$ & 0 & \\
\hline Negative & $53(72)$ & 0 & $53(100)$ & & $14(40)$ & $39(100)$ & \\
\hline p16 & & & & $<0.001$ & & & \\
\hline Positive & $35(47)$ & $21(100)$ & 0 & & $35(100)$ & 0 & \\
\hline Negative & $39(53)$ & 0 & 0 & & 0 & $39(100)$ & \\
\hline Induction response & & & & 0.436 & & & 0.018 \\
\hline$C R$ & $22(30)$ & $7(33)$ & $15(28)$ & & $15(43)$ & $7(18)$ & \\
\hline Non-CR & $52(70)$ & $14(67)$ & $38(72)$ & & $20(57)$ & $32(82)$ & \\
\hline RT dose (cGy) & & & & 0.429 & & & 0.470 \\
\hline$\geq 6,500$ & $43(58)$ & $6(67)$ & $37(57)$ & & $21(60)$ & $22(56)$ & \\
\hline$<6,500$ & $31(42)$ & $3(34)$ & $28(43)$ & & $14(40)$ & $17(44)$ & \\
\hline
\end{tabular}


Table 1 Patient and clinicopatholgic characteristics (Continued)

\begin{tabular}{|c|c|c|c|c|c|c|c|}
\hline RT type & & & & 0.070 & & & 0.289 \\
\hline 3D-RT & $52(80)$ & $5(56)$ & $47(84)$ & & $25(76)$ & $27(84)$ & \\
\hline IMRT & $13(20)$ & $4(44)$ & $9(16)$ & & $8(24)$ & $5(16)$ & \\
\hline Treatment duration & & & & 0.501 & & & 0.092 \\
\hline$<4$ months & $29(39)$ & $3(33)$ & $26(40)$ & & $17(49)$ & $12(31)$ & \\
\hline$\geq 4$ months & $45(61)$ & $6(67)$ & $39(60)$ & & $18(51)$ & $27(69)$ & \\
\hline
\end{tabular}

Abbreviation: $C R$, complete response.

\section{Results}

\section{Patient characteristics according to HPV status}

Eighty-seven patients were treated with induction chemotherapy followed by CRT for locally advanced OPC between June 2004 and June 2011. Of these, 10 patients had no available tissue and 3 patients received one cycle of induction chemotherapy without follow-up examination; therefore, 74 patients were enrolled in this study. Five patients received two cycles of induction chemotherapy and 69 patients completed three cycles of chemotherapy. After induction chemotherapy, one patient received salvage surgery and eight were not given radiotherapy due to their poor general condition. Therefore, 65 patients (88\%) received CRT. Based on genotype, HPV + was detected in 21 patients (28\%), while 35 patients $(47 \%)$ showed p16+ expression by IHC analysis. In the HPV genotype analysis, 16 patients (76\%) were positive for genotype 16, 6 (29\%) for genotype 18 and one each for genotypes 33 and 35 . Among these, three patients were positive for both genotypes 16 and 18. The correlation between $\mathrm{HPV}+$ and $\mathrm{p} 16+$ expression was statistically significant $(p<0.001)$. Tumor site and HPV status were not related. Among the characteristics of the patients, smoking history (never smoking) and performance status (PS; PS 0) were significantly associated with HPV and p16 (Table 1).
Expression of p53, class III beta-tubulin, ERCC1 and bcl-2 differed according to HPV status

p53, class III beta-tubulin, bcl-2 and ERCC1 expression were not correlated with clinical stage, with the exception of a trend towards an early $\mathrm{T}$ stage in $\mathrm{p} 16+$ patients $(p=0.062)$. However, $\mathrm{p} 53$ and class III beta-tubulin expression were significantly higher in HPV- and p16- than $\mathrm{HPV}+$ and p16+ patients (Table 2). Conversely, bcl-2 expression was greater in HPV + or p16+ than HPV- or p16- patients. ERCC1 expression did not differ significantly according to HPV status. There was no significant difference between HPV genotype and protein expression. Non-smokers showed more frequent $\mathrm{HPV}+(p=0.047)$ and $\mathrm{p} 16+(p=0.005)$ than smokers. However, expression of p53, ERCC1, and class III beta-tubulin were not associated with smoking history.

\section{Treatment outcome and survival according to CRT} response and protein status

A CR to induction chemotherapy was observed in 22 patients (30\%) and a partial response in 46 patients (62\%). Subsequent CRT after induction chemotherapy was performed in 65 patients. Among them, 37 patients (57\%) showed CR and 6 patients (9\%) who showed partial response received salvage operation. The $C R$ rate

Table 2 The expression of p53, ERCC1, beta-tubulin and bcl-2 stratified by HPV and p16 status

\begin{tabular}{|c|c|c|c|c|c|c|c|}
\hline & \multirow{2}{*}{$\begin{array}{l}\text { Total } \\
n(\%)\end{array}$} & \multicolumn{3}{|c|}{ HPV status, $n(\%)$} & \multicolumn{3}{|c|}{ p16 status, $n(\%)$} \\
\hline & & Positive & Negative & $p$ & Positive & Negative & $p$ \\
\hline p53 & & & & $<0.001$ & & & $<0.001$ \\
\hline Low & $49(66)$ & $20(95)$ & $29(55)$ & & $32(91)$ & $17(44)$ & \\
\hline High & $25(34)$ & $1(5)$ & $24(45)$ & & $3(9)$ & $22(56)$ & \\
\hline ERCC1 & & & & 0.329 & & & 0.422 \\
\hline Low & $34(46)$ & $11(52)$ & $23(43)$ & & $17(49)$ & $17(44)$ & \\
\hline High & $40(54)$ & $10(48)$ & $30(57)$ & & $18(51)$ & $22(56)$ & \\
\hline Class III beta tubulin & & & & 0.002 & & & 0.001 \\
\hline Low & $52(70)$ & $20(95)$ & $32(60)$ & & $31(89)$ & $21(54)$ & \\
\hline High & $22(30)$ & $1(5)$ & $21(40)$ & & $4(11)$ & $18(46)$ & \\
\hline $\mathrm{BCl}-2$ & & & & 0.003 & & & 0.006 \\
\hline Low & $57(77)$ & $11(52)$ & $46(87)$ & & $22(63)$ & $35(90)$ & \\
\hline High & $17(23)$ & $10(48)$ & $7(13)$ & & $13(37)$ & $4(10)$ & \\
\hline
\end{tabular}


after induction chemotherapy was significantly higher in $\mathrm{p} 16+(43 \%)$ than $\mathrm{p} 16-(18 \%)$ patients $(p=0.018)$, and HPV was not associated significantly with the CR rate. There was no significant difference in chemotherapy response according to HPV genotypes. Patients who did not show a CR after induction chemotherapy tended to express a higher level of $\mathrm{p} 53$ than CR patients regardless of HPV status ( $p=0.055)$; however, expression of ERCC1, class III beta-tubulin and bcl-2 were not associated significantly with a CR. During follow-up (median 48.3 months) period, 30 patients had progressive disease and 24 died. The median PFS and OS were not reached at the time of analysis. The 3Y-PFS and 3Y-OS rate were $53.4 \pm 6.5 \%$ (95\% CI, $40.66-66.14)$ and $70.3 \pm 5.5 \%$ (95\% CI, 59.52 81.08), respectively. 3Y-PFS showed a greater trend in $\mathrm{HPV}+(p=0.078$ Figure $1 \mathrm{~B})$ or $\mathrm{p} 16+(p=0.076$ Figure $1 \mathrm{~A})$ than HPV- or p16- patients. In the OS analysis, the 3Y-OS in p16+ patients was significantly higher $(82.9 \%, 95 \% \mathrm{CI}$ 70.36 - 95.44) than in p16- patients $(58.9 \%, 95 \%$ CI 42.63 $75.17, p=0.014$, Figure 1C, D).
In univariate analyses, clinical features such as an early $\mathrm{T}$ stage (T1-2 rather than T3-4) and good PS (PS 0 ) were significantly associated with the $3 Y-P F S$ rate. In addition, PS (PS 0) and achievement of CR, completion of RT ( $\geq 6,500$ cGy) showed a significantly better $3 Y-O S$ rate than the other OS rates (Table 3). The expression of p53, ERCC1, class III beta-tubulin and bcl-2 did not influence the 3Y-PFS rate. However, p16, low p53 $(p=0.002)$ and class III beta-tubulin $(p=0.012)$ expression were significantly related to a higher $3 \mathrm{Y}-\mathrm{OS}$ rate than was high expressions. In multivariate analyses, early $\mathrm{T}$ stage $(p=0.036)$ and PS $0(p=0.029)$ showed a better 3Y-PFS rate compared to late $\mathrm{T}$ stage or PS 1 . In the $3 \mathrm{Y}-\mathrm{OS}$ rate, low p53 expression $(p=0.012)$ and a CR $(p=0.026)$ were significant prognostic factors for the 3 Y-OS rate (Table 4). When the patients were divided into four groups according to p16 positivity and p53 expression (low and high), the OS was significantly greater in p16+/p53 low expression patients than other groups $(p=0.010$, Figure $2 \mathrm{~B})$.
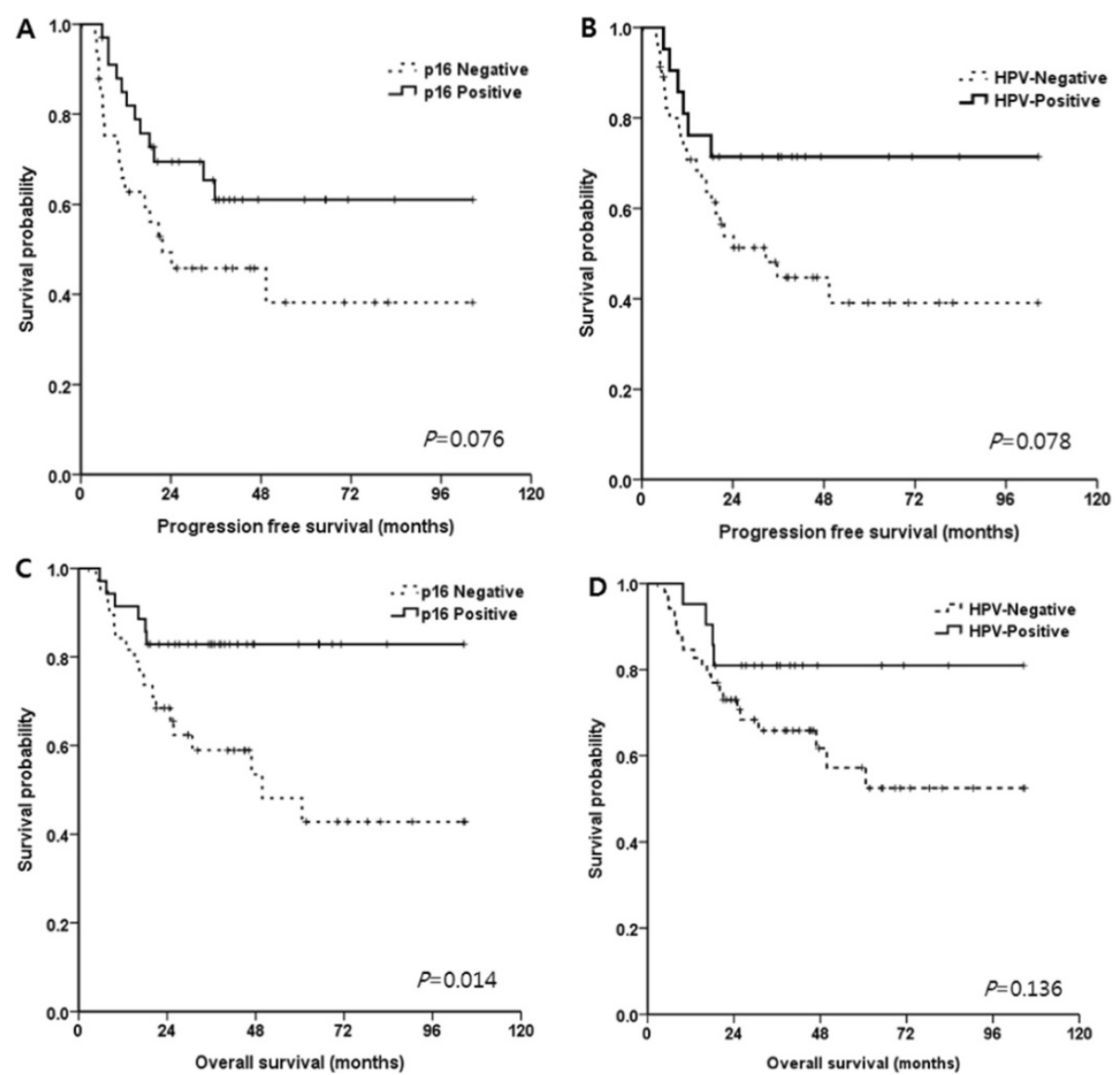

Figure 1 PFS and OS according to HPV and p16 expression. The 3Y-PFS showed a greater trend in p16+ or HPV+ than p16- or HPV-patients (A, B). In the OS analysis, the 3Y-OS in p16+ patients was significantly higher than in p16- patients (C). However, there was no statistical significance according to HPV status (D). 
Table 3 Univariate analysis for survival

\begin{tabular}{|c|c|c|c|c|}
\hline & 3Y-PFS, \% (95\% Cl) & $p$ & $3 Y-O S \%(95 \% \mathrm{CI})$ & $p$ \\
\hline Gender & & 0.301 & & 0.571 \\
\hline Male & $51(37.7-64.3)$ & & $70(58.3-80.7)$ & \\
\hline Female & $80(43.0-117.0)$ & & $80(44.9-115.1)$ & \\
\hline Smoking & & 0.793 & & 0.642 \\
\hline Never & $50(28.2-71.4)$ & & $73(55.4-89.9)$ & \\
\hline Ex/current & 55 (39.7-71.3) & & $69(55.7-82.7)$ & \\
\hline Alcohol & & 0.217 & & 0.338 \\
\hline Never/social & $56(42.0-70.6)$ & & $72(59.7-84.1)$ & \\
\hline Heavy & $45(21.0-69.6)$ & & $66(44.1-88.4)$ & \\
\hline Anatomic site & & 0.235 & & 0.563 \\
\hline Tonsil & $59(43.5-73.7)$ & & $71(57.7-84.4)$ & \\
\hline Others & $44(21.6-65.8)$ & & $69.2(51.4-87.0)$ & \\
\hline Clinical stage & & 0.952 & & 0.930 \\
\hline III & $54(39.4-68.8)$ & & $72(53.3-92.3)$ & \\
\hline IV & $53(38.5-67.5)$ & & $61(42.7-78.7)$ & \\
\hline T stage & & 0.005 & & 0.710 \\
\hline $\mathrm{T} 1-2$ & $63(47.7-79.1)$ & & $77(64.1-89.5)$ & \\
\hline T3-4 & $37(17.6-56.8)$ & & $61(42.7-78.7)$ & \\
\hline N stage & & 0.750 & & 0.805 \\
\hline No-1 & $54(39.4-68.8)$ & & $73(53.3-93.3)$ & \\
\hline N2-3 & $51(25.8-76.8)$ & & $69(56.3-81.7)$ & \\
\hline PS (ECOG) & & 0.004 & & 0.003 \\
\hline 0 & $62(44.3-80.0)$ & & $85(73.3-96.1)$ & \\
\hline 1 & $26(5.5-47.5)$ & & $52(34.4-69.6)$ & \\
\hline Induction response & & 0.549 & & 0.002 \\
\hline$C R$ & $53(29.2-75.8)$ & & 94 (91.8-105.8) & \\
\hline Non-CR & $54(39.2-69.0)$ & & $61(47.2-74.2)$ & \\
\hline RT dose (cGy) & & 0.233 & & 0.006 \\
\hline$\geq 6,500$ & $57(41.6-73.0)$ & & $80(67.5-92.5)$ & \\
\hline$<6,500$ & $46(24.7-67.1)$ & & $56(38.4-73.6)$ & \\
\hline RT type & & 0.132 & & 0.198 \\
\hline 3D-RT & $59(42.5-67.8)$ & & $74(62.0-86.4)$ & \\
\hline IMRT & $73(50.5-92.5)$ & & $88.1(78.1-98.1)$ & \\
\hline Treatment duration & & 0.702 & & 0.258 \\
\hline$<4$ months & $59(36.3-81.0)$ & & $75(58.4-91.0)$ & \\
\hline$\geq 4$ months & $53(36.6-68.8)$ & & $67(53.3-81.5)$ & \\
\hline HPV & & 0.078 & & 0.136 \\
\hline Positive & $71(52.0-90.8)$ & & $81(64.1-98.0)$ & \\
\hline Negative & $45(29.0-60.4)$ & & $66(52.5-79.1)$ & \\
\hline p16 & & 0.076 & & 0.014 \\
\hline Positive & $61(43.4-78.6)$ & & $83(70.4-95.4)$ & \\
\hline Negative & $46(28.2-63.4)$ & & $59(42.6-75.2)$ & \\
\hline p53 & & 0.655 & & 0.002 \\
\hline Low & $43(25.5-71.7)$ & & $81(69.8-92.2)$ & \\
\hline High & $49(28.0-58.2)$ & & $50(30.1-70.5)$ & \\
\hline
\end{tabular}


Table 3 Univariate analysis for survival (Continued)

\begin{tabular}{|c|c|c|c|c|}
\hline ERCC1 & & 0.491 & & 0.355 \\
\hline Low & $53(31.2-74.4)$ & & $64(48.3-78.9)$ & \\
\hline High & $54(26.8-82.0)$ & & 70 (41.3-99.3) & \\
\hline Class III beta tubulin & & 0.098 & & 0.012 \\
\hline Low & $58(43.1-72.5)$ & & $77(65.4-89.4)$ & \\
\hline High & $42(18.4-66.2)$ & & $54(32.5-74.9)$ & \\
\hline $\mathrm{BCl}-2$ & & 0.678 & & 0.217 \\
\hline Low & 57 (40.6-72.8) & & $64(48.3-78.9)$ & \\
\hline High & $54(26.8-82.0)$ & & $70(41.2-99.3)$ & \\
\hline
\end{tabular}

\section{Discussion}

This is the first report of differential expression of biomarkers between HPV OPC and non-HPV OPC under a single treatment strategy. HNSCC associated with OPC has a higher survival rate than non- OPC-associated HNSCC [4]; however, comparisons of biomarkers based on HPV status are lacking. In the current study we determined the protein expression profiles associated with OPC treatment outcomes. Radiotherapy is an important head-and-neck cancer treatment modality, but measuring the response is difficult due to radiationinduced tissue swelling. Therefore, we selected patients treated with induction chemotherapy. To avoid bias due to use of different chemotherapy regimens, the induction regimen was limited to a combination chemotherapy using DCF.

Previous studies reported the prognostic role of biomarkers in head and neck cancers $[17,18,25]$. Among them, p53 is a well-known biomarker for various tumors, including head-and-neck cancers [17]. In HPV OPC, p53 is usually not mutated, but its expression is low due to HPV E6 protein activity, which targets p53 for ubiquitination and degradation [9]. This phenomenon may preserve the apoptotic function of p53 even though its level is low, and thus enable radiation-induced apoptosis [26]. The p53 status is an important factor in the treatment response and may indicate different treatment outcomes among HNSCC patients, including those with OPC $[12,16]$. Reportedly, p53 missense mutation increases protein stability, which is easily detected by IHC [17]. In addition, beta tubulin has been investigated extensively in patients treated with taxane for various types of cancer $[20,25,27]$. In the TAX 324 study, class II beta-tubulin expression was examined in locally advanced head-andneck cancer (LAHNC) patients treated with induction chemotherapy with DCF or 5-FU with cisplatin [25]. It suggested that high expression of class II beta tubulin showed adverse treatment outcome after induction chemotherapy. On the other hand, we reported the predictive role of class III beta-tubulin in gastric cancer treated with taxane-based chemotherapy [20]; a similar finding was reported in LAHNC patients [18]. Based on this premise, we evaluated class III beta-tubulin in this study.

In the present study, HPV OPC occurred frequently in young adults, non-smokers and good PS patients. However, the clinical characteristics and protein expression associated with chemotherapy response differed significantly according to HPV status. p53 and class III beta-tubulin were more highly expressed in non-HPV OPC than HPV OPC patients. However, the relationship between p53 and smoking was not established in this study, and could be related to the medical records depend on patient history. Low p53 expression was significantly correlated with a CR to induction chemotherapy, and was a good prognostic factor in the multivariate analysis. Therefore, p53 had high prognostic value for OPC. Interestingly, three patients showed p53 high/p16+, and they showed inferior 3Y-PFS and 3Y-OS than p53 low/p16+ patients. It means that the pathogenesis could

Table 4 Multivariate analysis for survival

\begin{tabular}{|c|c|c|c|c|}
\hline & $3 Y$ PFS HR $(95 \% \mathrm{Cl})$ & $p$ & $3 Y-O S$ HR $(95 \% \mathrm{Cl})$ & $p$ \\
\hline T (1-2 vs. 3-4) & $2.218(1.054-4.668)$ & 0.036 & - & \\
\hline PS (ECOG 0 vs. 1) & $2.341(1.093-5.017)$ & 0.029 & & \\
\hline p53 (low vs. high) & - & & $2.863(1.261-6.500)$ & 0.012 \\
\hline Postinduction CR (CR vs. non-CR) & - & & $9.847(1.322-73.372)$ & 0.026 \\
\hline
\end{tabular}

Abbreviation: $C R$ complete response. 

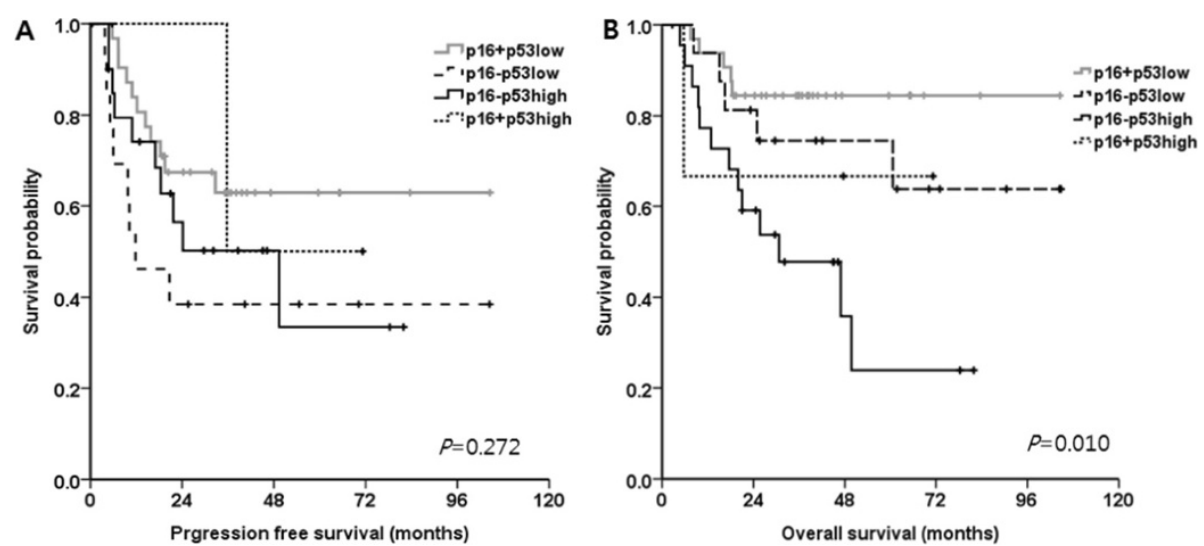

Figure 2 PFS and OS based on p16 positivity and p53 expression. PFS was not different according to p16 positivity and p53 expression (A) OS was significantly greater in p16+/p53 low expression patients than other groups (B).

be combined with HPV and other factors. Therefore, although the number is small, p16 positivity itself could be lacking to predict the treatment outcome in OPC. Class III beta-tubulin was also highly expressed in nonHPV patients and was associated with a poor 3Y-OS. The anti-apoptotic factor bcl-2 was more highly expressed in HPV-OPC than non-HPV OPC patients, and had no effect on chemotherapy response or survival. In general, high bcl-2 expression shows a poor response to chemotherapy or radiotherapy in solid tumors [28-30]. However, reports regarding high bcl-2 expression predicting a good response in HNSCC [21,25] or lung cancer [31] are conflicting. To define the role of bcl-2, we analyzed bcl- 2 expression according to HPV status. The OS in p16+ patients did not differ according to the bcl-2 expression level (83.4 months for low expression, 78.4 months for high expression). In contrast, although the number of patients was insufficient to achieve statistical significance, low bcl-2 expression (63.2 months) showed a trend to a better OS compared to high bcl-2 expression (20.5 months) in p16- patients. This result suggested that although bcl-2 was highly expressed in p16+ OPC patients, other mechanisms (e.g., lower p53 or class III beta-tubulin expression) might act individually or in concert to modulate proapoptosis when exposed to chemotherapy and overcome chemoresistance of bcl-2. However, in p16- patients, bcl-2 has an anti-apoptotic function with strong expression of p53 and class III beta tubulin. Confirming the role of bcl-2 in various types of cancer of heterogeneous causes is difficult; therefore, further studies with larger cohorts that include other biomarkers are necessary to define the role of bcl-2.

In multivariate analysis, PFS was associated with clinical characteristics such as early $\mathrm{T}$ stage and good PS score, rather than biochemical markers. However, p53 and class III beta-tubulin expression levels were significant prognostic factors in terms of OS. CR after induction chemotherapy was also associated with good survival, and patients who showed a CR tended to express lower levels of p53 compared to non-CR patients, suggesting the important factors associated with prognosis are related to biological characteristics other than tumor stage. This may be a reasonable basis for de-escalation treatment trials in HPV OPC patients. Regardless of HPV status, completion of radiotherapy is an important prognostic factor for OS in univariate analysis $(p=0.006)$.

To investigate the effects of HPV in OPC, an optimal detection method is important. In a clinical setting, specificity, sensitivity and convenience are necessary for treatment planning. In terms of sources, paraffin-embedded tissue is more easily obtained than fresh tissue. The direct detection methods for HPV infection are polymerase chain reaction (PCR) and in situ hybridization (ISH). Both are highly specific for detection of HPV infection, but PCR does not distinguish the presence of transcriptionally inactive viral DNA or enable identification of crosscontamination of samples that may lead to false-positive results [32]. ISH assays capable of detecting multiple high-risk HPV types have lower sensitivity than PCR. IHC staining for p16 has been substituted for HPV PCR or ISH for HPV detection because p16 overexpression indicated the presence of active and functional viral oncoprotein and is readily detected in paraffin-embedded tissue. In the present study, all HPV + patients $(\mathrm{n}=28)$ were p16+; however, 19 patients were p16+ but HPVbased on PCR. In survival subgroup analysis, the survival outcomes of $\mathrm{HPV}+/ \mathrm{p} 16+$ and $\mathrm{HPV}-/ \mathrm{p} 16+$ patients showed similar trends contrast to HPV-/p16- patients. The discrepancy between p16+ and HPV PCR-patients may be associated with functional $\mathrm{pRb}$ disturbances unrelated to the HPV infection (e.g., mutational inactivation of $\mathrm{Rb}$ protein) $[33,34]$. Therefore, $\mathrm{p} 16$ is a potential 
surrogate marker for the prognosis of OPC presenting of HPV infection in addition to show its functional status and easy availability.

The strength of the current study was the direct comparison of protein expression in OPC according to HPV status under the same treatment regimen, followed by CCRT. To date, several studies of OPC biomarkers using various chemotherapy regimens, radiotherapy or surgery $[17,18,25]$, have been conducted, which makes clarification of the roles of the biomarkers problematic. In addition, we documented the crucial role of p53, which was differentially expressed according to HPV status, influenced on CR and survival. However, the present study has several limitations. We did not adjust for multiple comparisons, which might lead to Type 1 error in statistical analysis. And other biomarkers such as EGFR, Ku80, thymidylate synthase or glutathione s-transferase (GST) were not evaluated. Therefore, larger studies are needed to confirm our findings including these biomarkers.

\section{Conclusions}

OPC showed distinct protein expression related with chemotherapy response according to HPV status. Low p53, class III beta-tubulin expression and high bcl-2 were expressed in HPV OPC compared to non-HPV OPC and these results suggest that better chemotherapy response of HPV OPC could be associated with different expression of these proteins. Among these biomarkers, p53 in addition to p16 could be used to design the individual treatment strategies for OPC.

\section{Competing interests}

The authors declare that they have no competing interests.

\section{Authors' contributions}

MJK and SHC drafted the manuscript. MSK, KK collected the clinical data. JEH, HJS, WKB, SHC, and IJC performed the chemotherapy and revised the manuscript. DHL, JKL, TMY, SCL supported the physical examination and operation. HSL checked the dental care. JUC and WKC performed the radiotherapy. YDC analyzed the pathological data. SHC conceived of the study and approved the final manuscript. All authors read and approved the final manuscript.

\section{Acknowledgements}

We thank Ji-Hee Lee and Mi-Ra Park for performing HPV PCR study. We also thank Yoo-Duk Choi for conducting the pathological data analyses. This research was sponsored by a grant (HCRI14027-21) from the Chonnam National University Hwasun Hospital Institute for Biomedical Science. The English in this document has been checked by at least two professional editors, both native speakers of English. For a certificate, please see: http://www.textcheck.com/certificate/XUqFdo.

\section{Author details}

${ }^{1}$ Department of Hematology-Oncology, Chonnam National University Hwasun Hospital, 322 Seoyangro, Hwasun, Jeollanamdo 519-763, Republic of Korea. ${ }^{2}$ Department of Otolaryngology-Head and Neck Surgery, Chonnam National University Hwasun Hospital, Jeollanamdo, Republic of Korea. ${ }^{3}$ Department of Radiation Oncology, Chonnam National University Hwasun Hospital, Jeollanamdo, Republic of Korea. ${ }^{4}$ Department of Dentistry, Chonnam National University Hwasun Hospital, Jeollanamdo, Republic of Korea. ${ }^{5}$ Department of Pathology, Chonnam National University Hwasun Hospital, Jeollanamdo, Republic of Korea.
Received: 8 June 2014 Accepted: 24 October 2014

Published: 7 November 2014

\section{References}

1. Frisch $M$, Hjalgrim $H$, Jaeger $A B$, Biggar RJ: Changing patterns of tonsillar squamous cell carcinoma in the United States. Cancer Causes Control 2000, 11(6):489-495.

2. Nasman A, Attner P, Hammarstedt L, Du J, Eriksson M, Giraud G, Ahrlund-Richter S, Marklund L, Romanitan M, Lindquist D, Ramqvist T, Lindholm J, Sparén P, Ye W, Dahlstrand H, Munck-Wikland E, Dalianis T: Incidence of human papillomavirus (HPV) positive tonsillar carcinoma in Stockholm, Sweden: an epidemic of viral-induced carcinoma? Int J Cancer 2009, 125(2):362-366.

3. Shin A, Jung YS, Jung KW, Kim K, Ryu J, Won YJ: Trends of human papillomavirus-related head and neck cancers in Korea: national cancer registry data. Laryngoscope 2013, 123(11):E30-E37.

4. Ang KK, Harris J, Wheeler R, Weber R, Rosenthal DI, Nguyen-Tan PF, Westra WH, Chung CH, Jordan RC, Lu C, Kim H, Axelrod R, Silverman CC, Redmond KP, Gillison ML: Human papillomavirus and survival of patients with oropharyngeal cancer. N Engl J Med 2010, 363(1):24-35.

5. Fakhry C, Westra WH, Li S, Cmelak A, Ridge JA, Pinto H, Forastiere A, Gillison $\mathrm{ML}$ : Improved survival of patients with human papillomavirus-positive head and neck squamous cell carcinoma in a prospective clinical trial. J Natl Cancer Inst 2008, 100(4):261-269.

6. Ragin CC, Taioli E: Survival of squamous cell carcinoma of the head and neck in relation to human papillomavirus infection: review and meta-analysis. Int J Cancer 2007, 121(8):1813-1820.

7. Robinson M, Sloan P, Shaw R: Refining the diagnosis of oropharyngeal squamous cell carcinoma using human papillomavirus testing. Oral Oncol 2010, 46(7):492-496.

8. Westra TA, Parouty M, Brouwer WB, Beutels PH, Rogoza RM, Rozenbaum $\mathrm{MH}$, Daemen T, Wilschut JC, Boersma C, Postma MJ: On discounting of health gains from human papillomavirus vaccination: effects of different approaches. Value Health 2012, 15(3):562-567.

9. Chung $\mathrm{CH}$, Gillison ML: Human papillomavirus in head and neck cancer: its role in pathogenesis and clinical implications. Clin Cancer Res 2009, 15(22):6758-6762

10. Braakhuis BJ, Snijders PJ, Keune WJ, Meijer CJ, Ruijter-Schippers HJ, Leemans $\mathrm{CR}$, Brakenhoff RH: Genetic patterns in head and neck cancers that contain or lack transcriptionally active human papillomavirus. J Natl Cancer Inst 2004, 96(13):998-1006.

11. Butz K, Geisen C, Ullmann A, Spitkovsky D, Hoppe-Seyler F: Cellular responses of HPV-positive cancer cells to genotoxic anti-cancer agents: repression of E6/E7-oncogene expression and induction of apoptosis. Int J Cancer 1996, 68(4):506-513.

12. Bristow RG, Benchimol S, Hill RP: The $\mathbf{p} 53$ gene as a modifier of intrinsic radiosensitivity: implications for radiotherapy. Radiother Oncol 1996, 40(3):197-223.

13. Olthof NC, Straetmans JM, Snoeck R, Ramaekers FC, Kremer B, Speel EJ: Next-generation treatment strategies for human papillomavirus-related head and neck squamous cell carcinoma: where do we go? Rev Med Virol 2012, 22(2):88-105.

14. Vermorken JB, Remenar E, Van Herpen C, Gorlia T, Mesia R, Degardin M, Stewart JS, Jelic S, Betka J, Preiss JH, van den Weyngaert D, Awada A, Cupissol D, Kienzer HR, Rey A, Desaunois I, Bernier J, Lefebvre JL, EORTC 24971/TAX 323 Study Group: Cisplatin, fluorouracil, and docetaxel in unresectable head and neck cancer. N Engl J Med 2007, 357(17):1695-1704.

15. Posner MR, Hershock DM, Blajman CR, Mickiewicz E, Winquist $E$, Gorbounova V, Tjulandin S, Shin DM, Cullen K, Ervin TJ, Murphy BA, Raez LE, Cohen RB, Spaulding M, Tishler RB, Roth B, Viroglio Rdel C, Venkatesan V, Romanov I, Agarwala S, Harter KW, Dugan M, Cmelak A, Markoe AM, Read PW, Steinbrenner L, Colevas AD, Norris CM Jr, Haddad RI, TAX 324 Study Group: Cisplatin and fluorouracil alone or with docetaxel in head and neck cancer. N Engl J Med 2007, 357(17):1705-1715.

16. Temam S, Flahault A, Perie S, Monceaux G, Coulet F, Callard P, Bernaudin JF, St Guily $\lrcorner$, Fouret P: p53 gene status as a predictor of tumor response to induction chemotherapy of patients with locoregionally advanced squamous cell carcinomas of the head and neck. J Clin Oncol 2000, 18(2):385-394 
17. Shinohara S, Kikuchi M, Tona R, Kanazawa Y, Kishimoto I, Harada H, Imai Y, Usami Y: Prognostic impact of $\mathrm{p} 16$ and $\mathrm{p} 53$ expression in oropharyngeal squamous cell carcinomas. Jpn J Clin Oncol 2014, 44(3):232-240.

18. Koh Y, Kim TM, Jeon YK, Kwon TK, Hah JH, Lee SH, Kim DW, Wu HG, Rhee CS, Sung MW, Kim CW, Kim KH, Heo DS: Class III beta-tubulin, but not ERCC1, is a strong predictive and prognostic marker in locally advanced head and neck squamous cell carcinoma. Ann Oncol 2009, 20(8):1414-1419.

19. Olaussen KA, Dunant A, Fouret P, Brambilla E, Andre F, Haddad V, Taranchon E, Filipits M, Pirker R, Popper HH, Stahel R, Sabatier L, Pignon JP, Tursz T, Le Chevalier T, Soria JC, IALT Bio Investigators: DNA repair by ERCC1 in non-small-cell lung cancer and cisplatin-based adjuvant chemotherapy. N Engl J Med 2006, 355(10):983-991.

20. Hwang JE, Hong JY, Kim K, Kim SH, Choi WY, Kim MJ, Jung SH, Shim HJ, Bae WK, Hwang EC, Lee KH, Lee JH, Cho SH, Chung IJ: Class III beta-tubulin is a predictive marker for taxane-based chemotherapy in recurrent and metastatic gastric cancer. BMC Cancer 2013, 13:431.

21. Pena JC, Thompson CB, Recant W, Vokes EE, Rudin CM: BCl-xL and BCl-2 expression in squamous cell carcinoma of the head and neck. Cancer 1999, 85(1):164-170.

22. Greene FL: The American joint committee on cancer: updating the strategies in cancer staging. Bull Am Coll Surg 2002, 87(7):13-15.

23. Romero-Pastrana F: Detection and typing of human papilloma virus by multiplex PCR with type-specific primers. ISRN Microbiol 2012, 2012:186915.

24. Begum S, Gillison ML, Ansari-Lari MA, Shah K, Westra WH: Detection of human papillomavirus in cervical lymph nodes: a highly effective strategy for localizing site of tumor origin. Clin Cancer Res 2003, 9(17):6469-6475.

25. Cullen KJ, Schumaker L, Nikitakis N, Goloubeva O, Tan M, Sarlis NJ, Haddad RI, Posner MR: Beta-Tubulin-II expression strongly predicts outcome in patients receiving induction chemotherapy for locally advanced squamous carcinoma of the head and neck: a companion analysis of the TAX 324 trial. J Clin Oncol 2009, 27(36):6222-6228.

26. Peltenburg LT: Radiosensitivity of tumor cells. Oncogenes and apoptosis. Q J Nucl Med 2000, 44(4):355-364.

27. Zhang HL, Ruan L, Zheng LM, Whyte D, Tzeng CM, Zhou XW: Association between class III beta-tubulin expression and response to paclitaxel/ vinorebine-based chemotherapy for non-small cell lung cancer: a meta-analysis. Lung Cancer 2012, 77(1):9-15.

28. Real PJ, Sierra A, De Juan A, Segovia JC, Lopez-Vega JM, Fernandez-Luna JL: Resistance to chemotherapy via Stat3-dependent overexpression of Bcl-2 in metastatic breast cancer cells. Oncogene 2002, 21(50):7611-7618.

29. Kamesaki S, Kamesaki H, Jorgensen TJ, Tanizawa A, Pommier Y, Cossman J: $\mathrm{BCl}-2$ protein inhibits etoposide-induced apoptosis through its effects on events subsequent to topoisomerase II-induced DNA strand breaks and their repair. Cancer Res 1993, 53(18):4251-4256.

30. Nix P, Cawkwell L, Patmore H, Greenman J, Stafford N: BCl-2 expression predicts radiotherapy failure in laryngeal cancer. Br J Cancer 2005, 92(12):2185-2189.

31. Jeong $\mathrm{SH}$, Jung JH, Han JH, Kim JH, Choi YW, Lee HW, Kang SY, Hwang YH, Ahn MS, Choi JH, Oh YT, Chun M, Kang S, Park KJ, Hwang SC, Sheen SS: Expression of $\mathrm{BCl}-2$ predicts outcome in locally advanced non-small cell lung cancer patients treated with cisplatin-based concurrent chemoradiotherapy. Lung Cancer 2010, 68(2):288-294.

32. Ritchie JM, Smith EM, Summersgill KF, Hoffman HT, Wang D, Klussmann JP, Turek LP, Haugen TH: Human papillomavirus infection as a prognostic factor in carcinomas of the oral cavity and oropharynx. Int I Cancer 2003, 104(3):336-344.

33. Gronhoj Larsen C, Gyldenlove $M$, Jensen DH, Therkildsen MH, Kiss K, Norrild B, Konge L, Von Buchwald C: Correlation between human papillomavirus and p16 overexpression in oropharyngeal tumours: a systematic review. Br J Cancer 2014, 110(6):1587-1594.

34. Marur S, D'Souza G, Westra WH, Forastiere AA: HPV-associated head and neck cancer: a virus-related cancer epidemic. Lancet Oncol 2010 11(8):781-789

doi:10.1186/1471-2407-14-824

Cite this article as: Kim et al: Different protein expression associated with chemotherapy response in oropharyngeal cancer according to HPV status. BMC Cancer 2014 14:824.

\section{Submit your next manuscript to BioMed Central and take full advantage of:}

- Convenient online submission

- Thorough peer review

- No space constraints or color figure charges

- Immediate publication on acceptance

- Inclusion in PubMed, CAS, Scopus and Google Scholar

- Research which is freely available for redistribution 